\title{
Challenges and strategies in managing food allergy: a patient and allergist perspective
}

\author{
$\mathrm{S} \mathrm{Xu}^{*}$, S Waserman, M Kastner, K Stawiarski, L Connors \\ From AllerGen NCE Inc.'s Fifth Annual Research Conference: Innovation from Cell to Society \\ Québec City, QC, Canada. 7-9 February 2010
}

\section{Objective/purpose}

Outpatient management of food allergy is suboptimal. Few studies have compared allergists' and patients' perspectives on food allergy management. Our goal was to assess patients' and caregivers' education experiences, learning needs, and confidence level in managing food allergy; and to examine allergists' teaching priorities, challenges, and strategies for caring for these patients. Our data provides feedback to health care providers that may lead to better management of food allergy.

\section{Methods}

This is a two-part observational study: an anonymous questionnaire completed by patients or caregivers in the clinic; and a qualitative interview with allergists. Using convenience sampling, patients were recruited from allergy clinics in Southern Ontario. Patients of any age with documented food allergy, who were seen by an allergist, were considered for inclusion. Outcomes were the learning needs of patients, and the management challenges faced by allergists and strategies to address them. Recorded allergist interviews were analyzed using content analysis of grounded theory methodology. Quantitative data were analyzed using descriptive statistics and frequency analysis.

\section{Findings}

Preliminary data were collected from 80 food allergic families (mean age was 9.5 years) and 5 allergists from community and academic centers in 4 cities. Sixty-one percent of patients were shown how to use an auto injector with a trainer and 51\% were asked to demonstrate its use. Fifty five percent of patients did not feel very confident about when to give an auto-injector, or how to administer it correctly (60\%) even though on

McMaster University Medical Center, Canada average, it was their third visit with the allergist. Top reasons for not feeling very confident include not using an auto injector in a real situation $(71 \%)$ and not feeling clear on indication of use (36\%). The majority of patients wanted more information on prevention and cure of food allergy (29\%), advancements in research (21\%), and how to avoid allergens (17\%). Allergists' priorities were to make an accurate diagnosis, and teach allergen avoidance and management of acute reactions. All allergists indicated a major challenge was to ensure correct technique and overcome reluctance to use auto injectors. Allergists found it helpful to provide frequent practice with trainers, provide written material and connect patients with support groups. Allergists indicated that anaphylaxis management needs to be incorporated into first aid courses and teacher/daycare provider training. In conclusion caregivers of food allergic patients lack confidence in acute management of reactions, which allergists recognize but find challenging to improve. More frequent demonstrations of auto injector use during clinic visits are needed. Furthermore, training that better stimulates real anaphylaxis reactions, including acute management, needs to be developed.

\section{Deliverables}

Our project will enable us to share educational experiences and goals of 100 food allergic patients in clinics across Southern Ontario. This is valuable feedback to participating allergists. Furthermore, data from allergist interviews will enable allergists to compare experiences and strategies to manage challenges in educating food allergic patients.

\section{Relevance}

Our study provides direction for improvement during allergy clinic visits, and strategies to address common challenges allergists face. This in turn will help improve 
patient care and quality of life for families living with food allergy. We aim to share our findings with patients and families through Anaphylaxis Canada, and with pediatricians across the country at the 2010 Canadian Pediatric Society Annual Conference.

Published: 26 November 2010

doi:10.1186/1710-1492-6-S3-P38

Cite this article as: $\mathrm{Xu}$ et al:: Challenges and strategies in managing

food allergy: a patient and allergist perspective. Allergy, Asthma \& Clinical

Immunology 2010 6(Suppl 3):P38.

Submit your next manuscript to BioMed Central and take full advantage of:

- Convenient online submission

- Thorough peer review

- No space constraints or color figure charges

- Immediate publication on acceptance

- Inclusion in PubMed, CAS, Scopus and Google Scholar

- Research which is freely available for redistribution

Submit your manuscript at www.biomedcentral.com/submit 